\title{
Rapid processing of fetal skin for prenatal diagnosis by light and electron microscopy
}

\author{
RAJ EADY, ${ }^{*}$ DB GUNNER, ${ }^{*}$ MJ TIDMAN, ${ }^{*} \mathrm{KH}$ NICOLAIDES, $\dagger \mathrm{CH}$ RODECK $\dagger$ \\ From the *Department of Electron Microscopy and Cell Pathology, Institute of Dermatology, Homerton \\ Grove, London E9, and †Harris-Birthright Research Centre for Fetal Medicine, King's College Hospital \\ Medical School, Denmark Hill, London SE5
}

SUMMARY A method has been developed for rapid processing of fetal skin for prenatal diagnosis of hereditary skin diseases by light and electron microscopy. Fixation, dehydration, embedding, and polymerisation can be achieved in about $5 \mathrm{~h}$. The quality of tissue preservation compares favourably with that produced by slower conventional techniques.

This procedure may provoke a wider interest in the potential use of fetal skin biopsy in prenatal diagnosis, especially if identification of structural abnormalities is a feasible alternative to more time consuming biochemical analysis.

Fetoscopy and fetal skin biopsy performed during the second half of the mid-trimester have recently become valuable techniques in the prenatal diagnosis of hereditary skin disease. ${ }^{2}$ This procedure, combined with light and usually electron microscopy, has now been successfully used in the prenatal diagnosis of epidermolysis bullosa of the lethal (junctional) $^{3}$ and recessive dystrophic ${ }^{4}$ types, bullous ichthyosiform erythroderma, ${ }^{5}$ harlequin ichthyosis, ${ }^{6}$ Sjögren-Larsson syndrome, ${ }^{7}$ anhydrotic ectodermal dysplasia, ${ }^{8}$ and oculocutaneous albinism. ${ }^{9}$

The fetal skin samples obtained during fetoscopy with special $\mathbf{2 0}$ gauge forceps are always extremely small (about $1 \mathrm{~mm}^{3}$ ), and it is critically important to achieve both adequate tissue fixation and correct orientation of the blocks for subsequent microscopical examination.

Our own studies using fetoscopic skin biopsy for prenatal diagnosis began in 1979, and we have now examined over $\mathbf{5 0}$ skin samples from more than $\mathbf{2 0}$ fetuses at risk for genetic skin disorders. ${ }^{2}$ Originally, we modified conventional processing techniques for electron microscopy and were able to provide a report between five and seven days after receiving the biopsy material. There is a need, however, for earlier results, especially in older pregnancies (at 20 weeks' gestation or later) not only to reduce the psychological stress on the parents but also because any delay in terminating an affected pregnancy is undesirable. We have therefore developed a rapid

Accepted for publication 7 March 1984 processing technique which takes about $5 \mathrm{~h}$ and allows electron microscopy to be carried out much sooner than normal.

\section{Material and methods}

We studied a total of 29 biopsy samples from 13 fetuses, aged 18 to 22 weeks. Eight pregnancies were at risk for epidermolysis bullosa letalis, one for epidermolysis bullosa dystrophica, two for oculocutaneous albinism, and one each was investigated for bullous and non-bullous ichthyosiform erythroderma.

In each case fetoscopy and fetal skin biopsy were performed according to the method we have described previously. ${ }^{3}$ The specimens are taken from the buttock or leg in fetuses at risk of having epidermolysis bullosa, and from the scalp or eyebrow for detection of albinism. The samples are literally pinched out of the skin with 20 gauge endoscopic forceps, the jaws of which are like two minute spoons with sharpened edges and hinged at one end. Inevitably, the tissue is subjected to considerable damage by crushing. In gross appearance the samples are irregularly shaped and about $1.5 \mathrm{~mm}$ in length and 0.5 to $1 \mathrm{~mm}$ in diameter.

The biopsy specimens are flushed from the for-

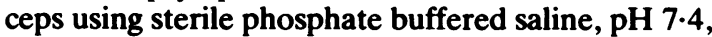
and immediately immersed in primary fixative. For samples possibly affected with epidermolysis bullosa division is not recommended because the simplest manipulation may cause detachment and loss of the epidermis. With other specimens, where there is no 
risk of dermo-epidermal separation, it is preferable to divide after primary fixation (see step 3 , below).

The following procedure was used, all steps being carried out at room temperature:

1 Primary fixation in half strength Karnovsky fixative $^{10}$ in $0.1 \mathrm{M}$ cacodylate buffer, $\mathrm{pH} 7 \cdot 4$, containing $5 \%$ sucrose and $0.05 \% \mathrm{CaCl}_{2}$ for $30 \mathrm{~min}$.

2 Wash in $0.1 \mathrm{M}$ cacodylate buffer, $\mathrm{pH} 7.4$, with same additives as in step 1.

3 Division of specimen, if required, before secondary fixation.

4 Secondary fixation in $2 \% \mathrm{OsO}_{4}$ in distilled water for $30 \mathrm{~min}$. Optional additives: $0.05 \mathrm{M}$ potassium ferricyanide, $\mathrm{K}_{3} \mathrm{Fe}(\mathrm{CN})_{6}$, or $0.05 \mathrm{M}$ potassium ferrocyanide, $\mathrm{K}_{4} \mathrm{Fe}(\mathrm{CN})_{6}{ }^{.1}$

5 Dehydration in graded alcohol: a single rinse, each for $5 \mathrm{~min}$, in $35,50,70$, and $95 \%$ ethanol, followed by two 5 min rinses in absolute ethanol.

6 Two rinses in propylene oxide for $5 \mathrm{~min}$.

7 Transfer to a 1:1 mixture of propylene oxide and Epon (TAAB "premix" hard) plus accelerator. Agitate for 15 min on rotary mixer.

8 Two changes of Epon with added accelerator for $1 \mathrm{~h}$ each on rotary mixer.

9 Orientation of blocks in flat embedding polyethylene moulds, and polymerisation at $100^{\circ} \mathrm{C}$ for $1 \mathrm{~h}$.

Specimens from two fetuses were processed using a more conventional protocol with overnight infiltration of resin and polymerisation at $100^{\circ} \mathrm{C}$ for $3 \mathrm{~h}$ instead of $1 \mathrm{~h}$.

Several blocks were treated with $5 \%$ uranyl acetate in $50 \%$ ethanol for $30 \mathrm{~min}$ at room temperature after the usual $50 \%$ ethanol dehydration step.

Semithin $(1 \mu \mathrm{m})$ sections were cut perpendicular to the skin surface to screen for epidermolysis bullosa or ichthyosis or along the axis of the hair follicles for albinism; ; sections were stained with methylene blue and azure $\mathrm{II}^{12}$ or with basic fuchsin and methylene blue. ${ }^{13}$ After selecting areas in the semithin sections which showed features for further ultrastructural examination, the blocks were trimmed and ultrathin sections cut with diamond knives. These sections were mounted on 150 mesh grids covered with Pioloform support films, stained with uranyl acetate and lead citrate,${ }^{14}$ coated with evaporated carbon under vacuum, and examined in a JEOL $100 \mathrm{CX}$ transmission electron microscope.

The total time taken for fixation, dehydration, embedding, and polymerisation was about $5 \mathrm{~h}$. Under ideal conditions electron microscopy could be performed 2 or $3 \mathrm{~h}$ after completion of processing.

More than 40 skin specimens, either from the same fetuses as those used in the rapid processing study or from others of a similar gestational age, were processed with conventional techniques ${ }^{3}$ and used as controls.

\section{Results}

All samples were affected by a variable degree of $\frac{}{\overline{0}}$ compression damage caused by the biopsy proce- $\frac{\bar{s}}{\bar{T}}$

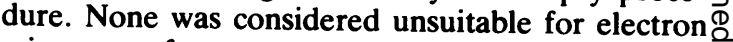
microscopy for any reason including biopsy artefact, inadequate sampling, or poor fixation. There were no problems which could be directly attributable to. poor embedding such as inadequate infiltration or $\vec{\omega}$ polymerisation. The blocks were consistently hard and evenly infiltrated and posed no special difficulty 용 for sectioning. They were not inferior to the blocks $\omega$ obtained by more conventional techniques, which ${ }_{0}$ entailed longer periods of fixation, infiltration, and polymerisation. ${ }^{2}$

The skin of 10 fetuses was found to be normal (Figs. 1 and 2). The quality of preservation varied from adequate to excellent and compared well with $\subseteq$ the samples that had been processed using conven- $\frac{\widehat{D}}{\sigma}$ tional rather than rapid procedures. In several $\vec{\bullet}$ instances the rapid technique seemed to produce $\infty$ superior fixation. There was no clear difference between the samples treated with the more rapid protocol and those which were subjected to overnight infiltration and $3 \mathrm{~h}$ polymerisation. In common with conventional processing, evidence of glycogen extraction was common, especially in the suprabasal epidermal cells, and gave rise to rather empty appearing cytoplasm or frank vacuolation. The addition of either potassium ferricyanide or potassium

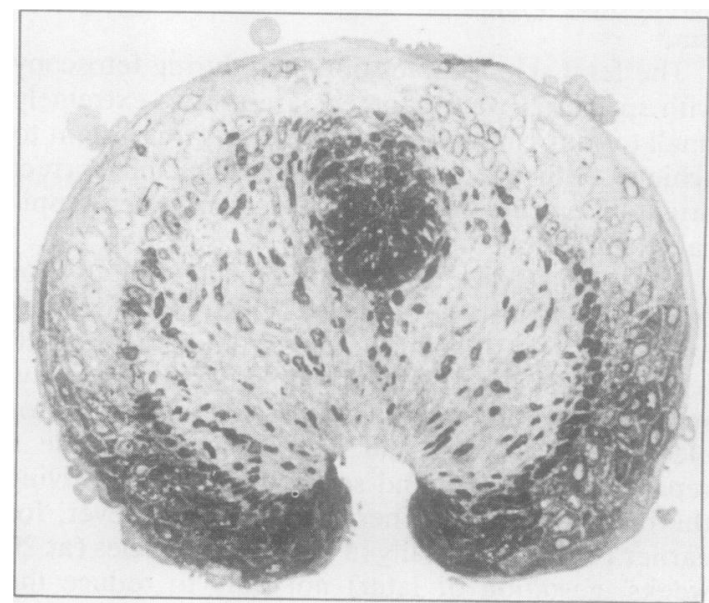

Fig. 1 Photomicrograph of transverse semithin Epon section of a normal skin biopsy specimen from an 18 week fetus. Note globular shape of sample with pinch biopsy artefact in lower portion. Methylene blue and azure II. Original magnification $\times 330$. 


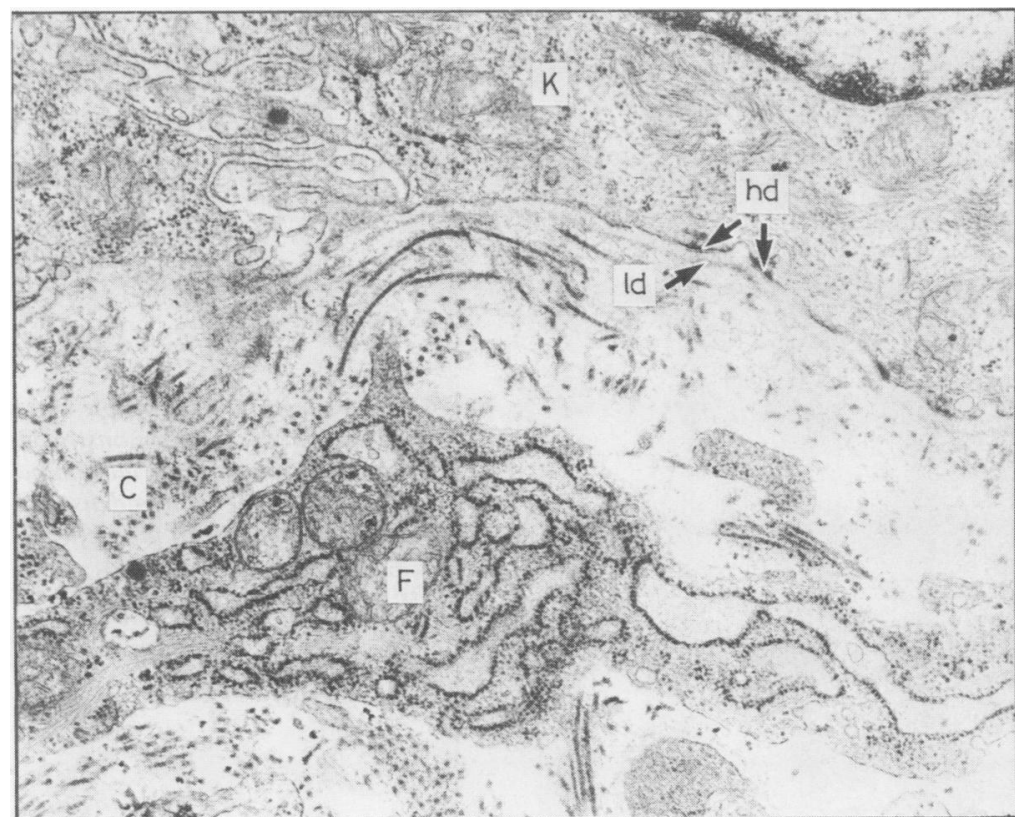

Fig. 2 Electron micrograph of normal dermo-epidermal junction and adjacent structures in 20 week fetus. $K$ = basal keratinocyte, hd $=$ hemidesmosomes, ld = lamina densa of basement membrane, $F=$ fibroblast, $C=$ collagen. Original magnification $\times 4700$.

ferrocyanide to the osmium tetroxide fixative (see step 4 in processing method) allowed better visualisation of glycogen through improved fixation and possibly decreased extraction, in addition to enhanced staining"1 (Eady, Gunner, and Kennedy, unpublished observation).
Other structures which appeared to be well preserved and stained included the dermo-epidermal junction, fibroblasts and surrounding collagen (Fig. 2), endothelial cells, Schwann cells with their axonal complexes, and perineural cells.

Two fetuses were affected with epidermolysis bul-

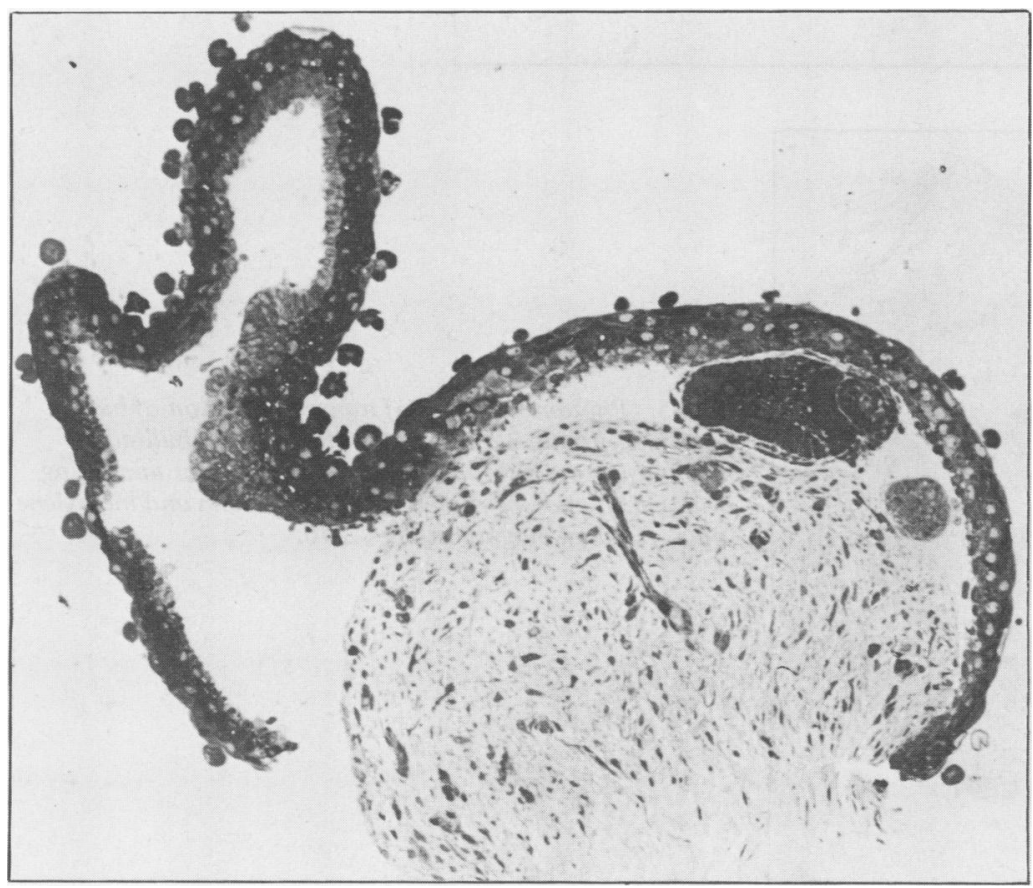

Fig. 3 Photomicrograph showing dermo-epidermal separation in 18 week fetus affected with epidermolysis bullosa letalis. Methylene blue and azure II. Original magnification $\times 180$. 


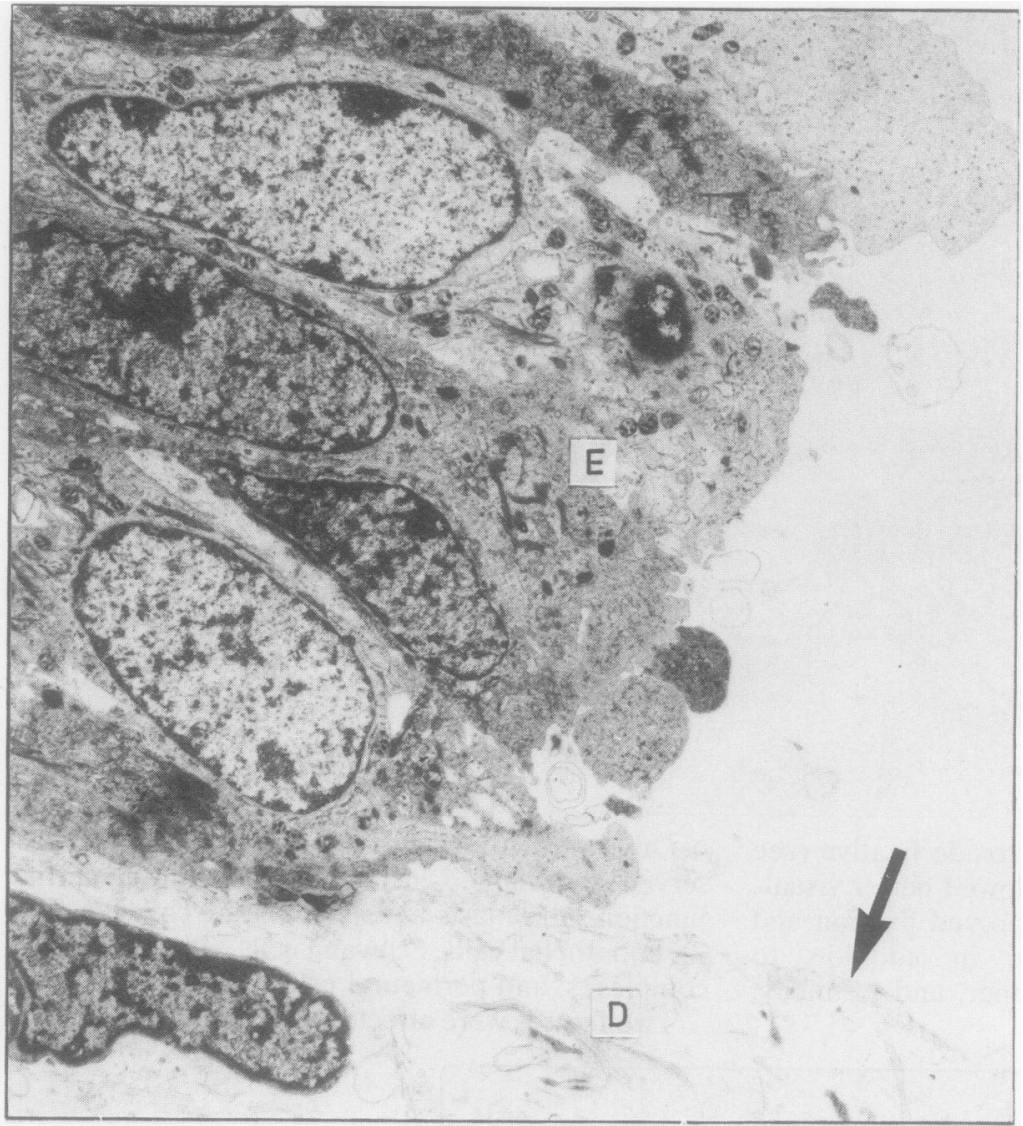

Fig. 4 Electron micrograph showing that the split demonstrated in Fig. 3 has occurred in the lamina lucida leaving the lamina densa (arrow) at the floor of the cleft. $E=$ epidermis, $D=$ dermis. Original magnification $\times 5200$.

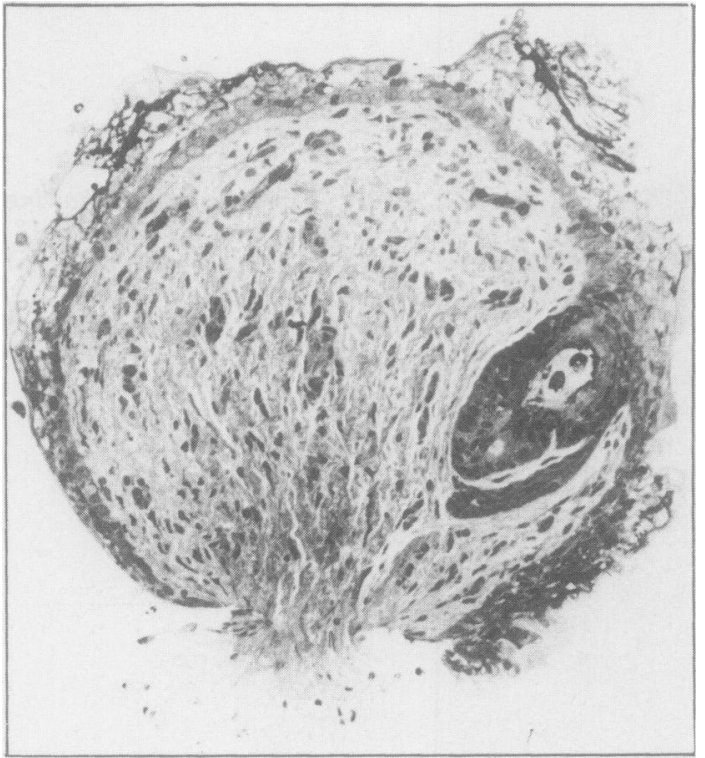

Fig. 5 Photomicrograph of transverse section of biopsy specimen from a 20 week fetus affected with bullous ichthyosiform erythroderma showing irregular thickening with vacuolation of epidermis. Basic fuchsin and methylene blue. Original magnification $\times 240$. 
losa letalis. Biopsy samples from these fetuses showed an extensive cleft in the dermo-epidermal junction by light microscopy (Fig. 3) which, on electron microscopy, was found to occur in the lamina lucida (Fig. 4), the characteristic site of blister formation in this disease. Blisters had not been noted during fetoscopy and we presume that in these cases, in common with four others also found to be affected (Eady, unpublished observations), the biopsy trauma was sufficient to cause dermo-epidermal separation.

In a further case the highly characteristic morphological abnormalities of bullous ichthyosiform erythroderma (epidermolytic hyperkeratosis) were noted. At the light microscope level these consisted of cytoplasmic vacuolation of all epidermal cell layers above the basal layer, abnormal cytoplasmic inclusions, and irregular epidermal thickening (Fig. 5). Electron microscopy showed that the abnormal cellular inclusions comprised large dense clumps of tonofilaments - an ultrastructural marker of the disease (Fig. 6).

\section{Discussion}

Our results indicate that the rapid processing of fetal skin biopsy samples obtained in utero during the mid-trimester for light and electron microscopy is a valuable technique for prenatal diagnosis. Tissue preservation and the quality of the blocks for microtomy compare favourably with control tissue treated with more time consuming conventional techniques. Factors which contribute to the success of the procedure and allow rapid penetration of the fixatives and other reagents include the very small size of the samples and the composition of fetal skin, which contains less collagen than postnatal dermis.

We have obtained excellent results with a modified standard fixation, dehydration, and embedding protocol known to be suitable for adult skin and have not found it necessary to use a resin with a lower viscosity than Epon, such as Spurr.

Other authors using rapid techniques for electron microscopy of a variety of animal tissues ${ }^{15-17}$ and for diagnostic purpose ${ }^{17} 18$ have also found tissue preservation obtained with fast methods equal or superior to that associated with a conventional slower technique.

Until now we have chiefly investigated congenital blistering disorders characterised by specific ultrastructural abnormalities within the epidermis or dermo-epidermal junction. The good preservation of dermal elements, including fibroblasts, endothelial and nerve cells, in addition to collagen fibres, suggests that this technique may have wider applications in prenatal diagnosis, perhaps in the detection of collagen diseases or lysosomal storage disorders.

We thank the Dystrophic Epidermolysis Bullosa Research Association and the Dunhill Trust for generous financial support. MJT is a recipient of an MRC Training Fellowship.

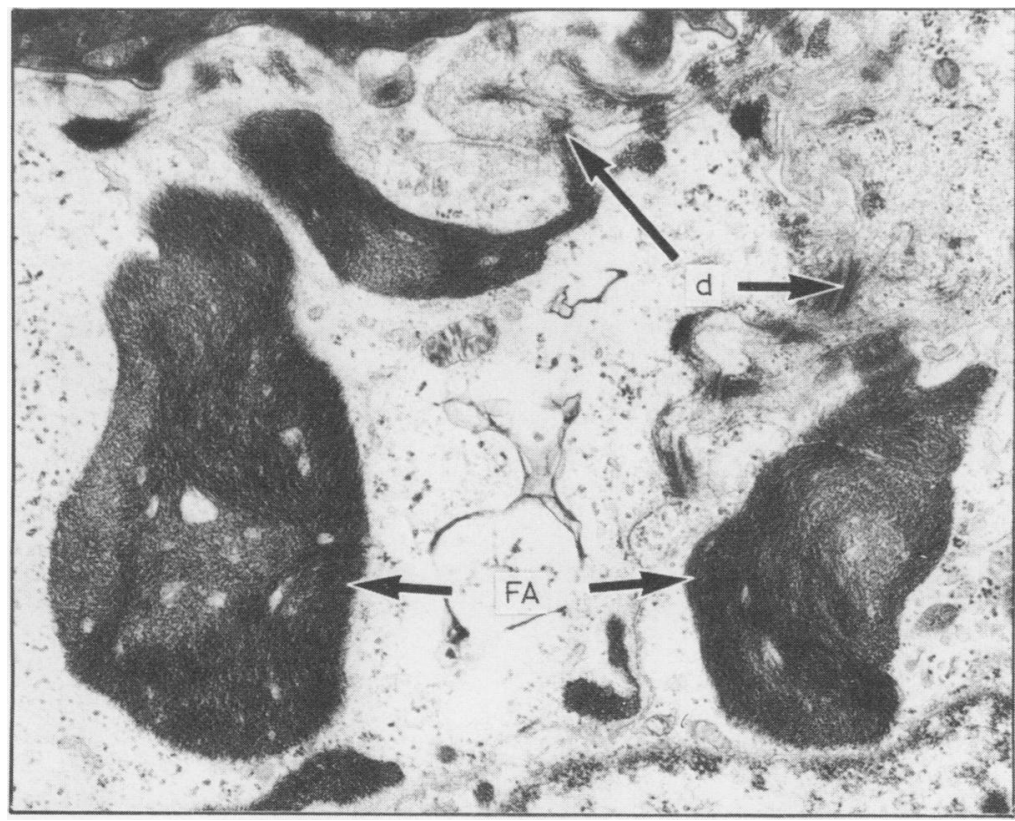

Fig. 6 Electron micrograph of parts of adjacent mid-epidermal cells from same block represented in Fig. 5. Tightly packed cytoplasmic flament aggregates (FA) are a diagnostic marker of this bullous disorder. $d=$ desmosomes. Original magnification $\times 23400$. 


\section{References}

${ }^{1}$ Rodeck CH, Nicolaides KH. Fetoscopy and fetal tissue sampling. Br Med Bull 1983;39:332-7.

${ }^{2}$ Eady RAJ, Rodeck CH. Prenatal diagnosis of disorders of the skin. In: Rodeck $\mathrm{CH}$, Nicolaides $\mathrm{KH}$, eds. Prenatal diagnosis. Proceedings of 11 th study group of the Royal College of Obstetricians and Gynaecologists. London: Royal College of Obstetricians and Gynaecologists. 1984:147-58.

${ }^{3}$ Rodeck CH, Eady RAJ, Gosden CM. Prenatal diagnosis of epidermolysis bullosa letalis. Lancet 1980; ;:949-52.

${ }^{4}$ Anton-Lamprecht I, Jovanovic V, Arnold M-L, Rauskolb R, Kern B, Schenk W. Prenatal diagnosis of epidermolysis bullosa dystrophica Hallopeau-Siemens with electron microscopy of fetal skin. Lancet 1981;ii:1077-9.

s Golbus MS, Sagebiel RW, Filly RA, Gindhart TD, Hall JG. Prenatal diagnosis of congenital bullous ichthyosiform erythroderma (epidermolytic hyperkeratosis) by fetal skin biopsy. $N$ Engl J Med 1980;302:93-5.

- Elias A, Mazur M, Sabbagha R, Esterly NB, Simpson JL. Prenatal diagnosis of harlequin ichthyosis. Clin Gen 1980; 17:275-80.

' Koussef BG, Matsouka LY, Stenn KS, Hobbins JC, Mahoney MJ, Hashimoto K. Prenatal diagnosis of Sjögren-Larsson syndrome. J Ped 1982; 101:998-1001.

${ }^{8}$ Anton-Lamprecht I, Arnold M-L, Rauskolb R, Schinzel A, Schmit W, Schnyder UW (Letters). Human Gen 1982;62:180.

9 Eady RAJ, Gunner DB, Garner A, Rodeck CH. Prenatal diagnosis of oculocutaneous albinism by electron microscopy of fetal skin. J Invest Derm 1983;80:210-2.

${ }^{10}$ Karnovsky MJ. A formaldehyde-glutaraldehyde fixative of high osmolarity for use in electron microscopy. $J$ Cell Biol 1965;27:137A.

"De Breuijn WC, Den Breejen P. Glycogen, its chemistry and morphological appearance in the electron microscope. III. Identification of the tissue ligands involved in the glycogen contrast staining reaction with osmium (VI)-iron(II) complex. Histochem J 1976;8:121-42.

${ }^{12}$ Richardson KC, Jarett L, Finke EH. Embedding in epoxy resin for ultrathin sectioning in electron microscopy. Stain Tech 1960;35:313-23.

${ }^{13}$ Huber JD, Parker F, Odland GF. A basic fuchsin and alkalinised methylene blue rapid stain for epoxy-embedded tissue. Stain Tech 1968;43:83-7.

${ }^{14}$ Reynolds ES. The use of lead citrate at high pH as an electronopaque stain in electron microscopy. J Cell Biol 1963, 17:208-12.

15 Estes LW, Apicella JV. A rapid embedding technique for electron microscopy. Lab Invest 1969;20:159-63.

${ }^{16}$ Hayat MA, Giaquinta R. Rapid fixation and embedding for electron microscopy. Tissue and Cell 1970;2:191-5.

${ }^{17}$ Bencosme SA, Tsutsami V. A fast method for processing biologic material for electron microscopy. Lab Invest 1970;23:447-50.

18 Johannessen JV. Rapid processing of kidney biopsies for electron microscopy. Kidney Int 1973;3:46-50.

${ }^{19}$ Rowden G, Lewis MG. Experience with a three-hour electron microscopy biopsy service. J Clin Pathol 1974;27:505-10.

Requests for reprints to: Dr RAJ Eady, Institute of Dermatology, Homerton Grove, London E9 6BX, England. 